\title{
DISPONIBILIDADE DE ENERGIA RADIANTE EM UM SISTEMA AGROFLORESTAL COM SERINGUEIRAS: PRODUTIVIDADE DO FEIJOEIRO $\left({ }^{1}\right)$
}

\author{
CIRO ABBUD RIGHI $\left({ }^{2 *}\right)$; MARCOS SILVEIRA BERNARDES $\left({ }^{2}\right)$
}

\begin{abstract}
RESUMO
O feijoeiro (Phaseolus vulgaris L.) adapta-se bem à radiação difusa, possibilitando seu cultivo em sistemas consorciados. O sistema agroflorestal (SAF) de seringueira (Hevea spp.) e feijoeiro é relatado em diversos países tropicais, com diversas vantagens em termos de produtividade e retorno econômico. Porém, os processos fisiológicos envolvidos na interação entre as duas espécies não estão devidamente compreendidos. Neste estudo, visou-se compreender os efeitos da modificação do ambiente pelas árvores na produtividade do feijoeiro, cultivado em SAF, em função de sua distância. Observo-se que a produtividade do feijoeiro está direta e positivamente relacionada à irradiância disponível, sendo diminuída com a proximidade das árvores. Assim, a mensuração ou estimativa da irradiância pode ser utilizada na predição do desempenho da leguminosa em SAF. O SAF proposto é adequado, visto que o excesso de radiação à cultura intercalar é atenuado pelas seringueiras durante o outono; no inverno, quando não ocorre este excesso, as seringueiras atenuaram menor porcentagem devido à queda de suas folhas. Não foram observadas diferenças no índice de colheita devido ao sombreamento; este, porém foi de 0,54 na semeadura de outono e de 0,38 na de inverno, parecendo ser característico para a cultura e a época de colheita.
\end{abstract}

Palavras-chave: Hevea spp., Phaseolus vulgaris, índice de colheita, produtividade, sistema de produção, luz.

\section{ABSTRACT \\ AVAILABLE RADIANT ENERGY IN AN AGROFORESTRY SYSTEM WITH RUBBER TRESS: THE PRODUCTIVITY OF COMMON BEANS}

It is observed a great adaptation of common beans (Phaseolus vulgaris L.) to diffuse light, making possible its cultivation in association with other crops. Agroforestry systems (AFS) of rubber trees (Hevea spp.) and beans are extensively reported in many tropical countries, with many advantages in productivity and economic revenue terms. However, the physiological processes involved in the interaction between these species are not well understood yet. This study was aimed to verify the effects of environment modification due to trees in the productivity of common beans grown in AFS as a function of their distance across the rubber tree planting line. It was observed that beans productivity is direct and positively related to irradiation availability, decreasing with the proximity of the trees. Thus irradiation measurement or simulation can be useful on predicting beans production in AFS. The proposed AFS is suitable, as radiation excess to the intercrop is attenuated by the rubber tress during the autumn; in winter, when this excess does not occur, rubber trees attenuated a smaller percentage due to their leaffall. It was not observed differences in harvest index due to shade; however these were 0.54 in autumn and 0.38 in winter seeming to be characteristic to the crop and harvest time.

Key words: Hevea spp.; Phaseolus vulgaris; harvest index; productivity; production system; light.

$\left({ }^{1}\right)$ Recebido para publicação em 11 de abril de 2006 e aceito em 6 de novembro de 2007.

$\left({ }^{2}\right)$ Departamento de Produção Vegetal, Escola Superior de Agricultura "Luiz de Queiroz" - ESALQ/USP, Caixa Postal 09, 13418-900 Piracicaba (SP). E-mail: carighi@yahoo.com $\left({ }^{*}\right)$ Autor correspondente; msbernar@esalq.usp.com.br 


\section{INTRODUÇÃO}

Sistema agroflorestal (SAF) é uma forma de uso da terra no qual as árvores crescem em associação com outras culturas ou animais, em vários arranjos espaciais e temporais, utilizando-se práticas de manejo compatíveis com o nível tecnológico dos agricultores envolvidos. Nos SAFs ocorrem interações ecológicas e econômicas entre as árvores e as outras culturas, resultando em vantagens comparativas a outros sistemas produtivos (NAIR, 1984; YOUNG, 1989). Com seu estudo, visa-se ao desenvolvimento de sistemas em que se propiciem a maximização de interações positivas e a minimização daquelas negativas. As três principais interações negativas são: a) sombreamento; b) competição por água e c) competição por nutrientes (Young, 1989).

O SAF de seringueira (Hevea spp.) e feijoeiro (Phaseolus vulgaris L.) é relatado em diversos países tropicais, também sendo utilizado no Brasil. Nesse sistema há diversas vantagens em termos de produtividade e de retorno econômico (FANCELLI, 1990; ZHU et al., 1981), porém, os processos fisiológicos envolvidos na interação entre as duas espécies não estão devidamente compreendidos. O entendimento básico de como os recursos disponíveis são utilizados no SAF é crucial para se estabelecer combinações de espécies, distribuição espacial, densidade de plantio e estratégias de manejo adequadas para os diferentes locais e condições (ONG et al., 1996, Willey e ReDDY, 1981).

BERNARDES (1993) postulou que o consórcio de feijoeiro em plantio de seringueira com espaçamento ampliado é viável durante toda a vida útil do seringal. Neste caso, com o SAF é promovida a redução dos custos de mão-de-obra de sangria das seringueiras, devido à grande produtividade por árvore, como observado por RIGHI (2000). A esta vantagem, combinase o uso eficiente das áreas não ocupadas com seringueira pela cultura do feijão, como resultado de maior espaçamento entre as árvores. O SAF de seringueira e feijoeiro é economicamente mais atrativo do que a seringueira em monocultura, se a perda de produtividade por área desta cultura for compensada pela maior produção por árvore somada à produção adicional de feijão - tanto na fase improdutiva como produtiva da seringueira.

Para permitir a total exploração do gradiente de energia radiante em um SAF, as plantas devem estar adaptadas. A eficiência do processo fotossintético está estritamente relacionada à distribuição e à interceptação da irradiância pelas diferentes plantas constituintes de um sistema (WHITE e IZquiERDO, 1989). Segundo VIEIRA (1985), a adaptação da planta utilizada em SAF deve ser no sentido de se manter uma fotossíntese líquida positiva aos diferentes níveis de irradiância. Existem três opções de adaptação à condição de diminuição da irradiância: a) diminuição da taxa respiratória, com redução do ponto de compensação luminosa; b) expansão da área foliar e assim aumento da área para captação de energia radiante e c) aumento da taxa fotossintética por unidade de área foliar e por unidade de energia radiante. GARDINER et al. (1979) e BURGA (1978) verificaram orientação fortemente horizontal nas folhas do feijoeiro; podem ser assumidas, porém, posições mais eretas em cultivos mais adensados. Deste modo, o coeficiente de extinção da luz (k) no feijoeiro é diminuído, permitindo maior interceptação da radiação pela copa. Para FAncelli (1987) e Vieira (1985), o feijoeiro é uma espécie muito bem adaptada às condições de consórcio devido, principalmente, ao seu reduzido ponto de saturação luminosa - cerca de um terço da radiação solar máxima nos trópicos.

A produtividade do feijoeiro e das demais plantas é resultado da repartição dos fotoassimilados, estabelecendo-se um balanço com interferência mútua entre as partes vegetativas e reprodutivas (WHITE e IZQUIERDO, 1989). Essa repartição pode ser afetada por vários fatores como os edáficos, disponibilidade de água, condições climáticas e manejo da cultura. Para VIEIRA (1967), no feijoeiro cultivado em consórcio com plantas de milho ou cafeeiros a produção é menor do que em comparação à cultura 'solteira'. Com a semeadura do feijoeiro nas entrelinhas do cafeeiro, pode-se ter diminuição da produtividade da rubiácea, devido à competição com a leguminosa pelo uso da água, em períodos mais secos, e de nutrientes em qualquer época. Cita que, no feijoeiro, nas várias modalidades de cultivo consorciado, a produtividade é dependente da densidade populacional, da distribuição espacial das plantas, das cultivares e das complexas relações ecológicas, principalmente da interação genótipo - ambiente. Регхото (1958) afirma que, com a redução da intensidade luminosa com o conseqüente aumento da umidade do solo e do ar e a redução das amplitudes térmicas, a produtividade do feijoeiro pode ser aumentada. Segundo BERNARDES et al. (1998), o sombreamento pelas seringueiras é a principal causa de redução de crescimento e produtividade de grãos em culturas intercaladas irrigadas, sendo a competição abaixo da superfície do solo restrita a uma menor distância a partir das árvores.

No presente estudo visou-se compreender os efeitos da modificação do ambiente luminoso pelo renque de seringueira na produtividade do feijoeiro. Hipotetizou-se que a produtividade do feijoeiro está direta e positivamente relacionada à disponibilidade de irradiância e que esta última pode ser descrita por modelo matemático. 


\section{MATERIAL E MÉTODOS}

\section{Avaliação da cultura consorciada}

O ensaio foi desenvolvido no seringal do campo experimental do Departamento de Produção Vegetal da ESALQ/USP, em Piracicaba (SP), localizado a $22^{\circ} 42^{\prime} 30^{\prime \prime} \mathrm{S}$ e $47^{\circ} 38^{\prime} 00^{\prime \prime} \mathrm{O}$. O campo era cultivado com seringueiras adultas com 13 anos de idade, com $15 \mathrm{~m}$ de altura em média, plantadas em espaçamento $7 \mathrm{~m} \times 3 \mathrm{~m}$, em Nitossolo vermelho eutroférrico (Terra Roxa Estruturada) e declividade de $1,5 \%$. A cultura do feijoeiro foi semeada em faixa ao lado das seringueiras em duas épocas: a) em 15 de março de 1999 (outono), e b) em 15 de julho de 1999 (inverno). Foram utilizadas sementes de feijoeiro (Phaseolus vulgaris L.) cv. Pérola, de hábito de crescimento indeterminado tipo II / III. O espaçamento adotado foi o de $0,45 \mathrm{~m}$ entre linhas, com 20 plantas por metro linear.

O delineamento experimental utilizado foi em blocos casualisados com quatro repetições. Cada parcela experimental constituiu-se de uma área de 15 $\mathrm{m} \times 30 \mathrm{~m}$, e em cada uma delas havia duas fileiras de seringueira, com seis árvores. A primeira fileira na interface com a cultura de feijoeiro é representativa de árvores em SAF em renque de linha dupla. A distância entre as parcelas ( $42 \mathrm{~m}$ ) era suficiente para impedimento da interferência mútua.

No manejo de ambas as culturas, incluindo-se irrigação por aspersão, evitaram-se limitações ao crescimento e à produção, exceto aquelas devidas aos tratamentos experimentais, como de competição por luz e abaixo da superfície do solo. A evapotranspiração da cultura do feijoeiro foi estimada pelo uso de um tanque Classe A instalado na área experimental. A lâmina de irrigação foi calculada de acordo com método proposto por Villa Nova e Sentelhas (1999), em que se estima a evapotranspiração da cultura pela medida do índice de área foliar (IAF) e da evaporação do tanque Classe A.

A produtividade e fitomassa dos feijoeiros foram mensuradas em função da distância das árvores quando aqueles estavam no estádio fenológico R9 (GEPTS e FernándeZ, 1982). Os tratamentos foram representados pelas posições de coleta situadas a 3,2; 4,$5 ; 6,3 ; 9,9 ; 14,4$ e $18,9 \mathrm{~m}$ de distância, contadas a partir da primeira fileira de plantio de seringueira e nas parcelas do tratamento de monocultivo, situadas a $50 \mathrm{~m}$ das árvores. Os grãos colhidos nas plantas retiradas em $1 \mathrm{~m}$ linear foram levados à estufa de ventilação forçada a $65^{\circ} \mathrm{C}$ até determinação de massa seca constante. Posteriormente, os valores de produtividade foram corrigidos para grãos com $12 \%$ de umidade, padrão para a comercialização de feijão.

\section{Medidas microclimáticas}

Nas mesmas posições de coleta de amostras de fitomassa, foi quantificada continuamente a disponibilidade de luz direta, refletida e transmitida pelas seringueiras à cultura intercalar, utilizando-se tubos solarímetros (TS-UM-3, Delta-T Devices) conectados a um sistema de aquisição de dados (Datalogger, Delta-T Devices). A irradiância disponível aos feijoeiros em monocultivo foi considerada como aquela mensurada por um piranômetro da estação meteorológica pertencente ao Departamento de Ciências Exatas - ESALQ/USP, localizada próxima ao experimento. Os sensores foram calibrados com base em aparelho padrão - EPPLEY.

Adotou-se o modelo matemático original proposto por GoudriaAn (1977) e adaptado por BERNARDEs et al. (1998), com o qual se calcula a irradiância relativa $\left(\mathbf{I}_{\mathbf{r}}\right)$ na cultura intercalar em função da distância da linha de seringueira (d em metros):

$$
I_{r}=\frac{1}{2} * \operatorname{sen}\left(\operatorname{arctg}\left(\frac{d-c_{w} * \frac{c_{w}}{d}}{H_{r}}+D\right)+1\right) * I_{0}
$$

em que, $\mathbf{I}_{\mathrm{r}}=$ irradiância diária $\left(\mathrm{MJ} \cdot \mathrm{m}^{-2}\right) ; \mathbf{I}_{0}=$ irradiância diária $\left(\mathrm{MJ} . \mathrm{m}^{-2}\right)$ numa superfície horizontal acima da copa das árvores; $\mathbf{c w}=$ largura da copa das árvores (m); $\mathbf{D}=$ declividade em radianos e $\mathbf{H}_{\mathrm{r}}=$ altura (m) relativa das árvores obtida pela seguinte equação:

$$
H_{r}=H_{a r v}-H_{c i}
$$

em que: $\mathbf{H}_{\text {árv. }}=$ altura das árvores $(\mathrm{m})$ e $\mathbf{H}_{\mathrm{ci}}=$ altura da cultura intercalar.

Os resultados foram analisados em delineamento de parcelas subdivididas em faixas (strip-plot), considerando-se cada posição de coleta de fitomassa do feijoeiro como um tratamento.

\section{RESULTADOS E DISCUSSÃO}

A cultura do feijoeiro semeada (a) em 15 de março de 1999 (outono) teve sua colheita de grãos em 30 de junho de 1999, perfazendo um ciclo de 107 dias; a semeada (b) em 15 de julho de 1999 (inverno) teve sua colheita de grãos em 30 de outubro de 1999, perfazendo também um ciclo de 107 dias.

A irradiância mensurada, bem como a estimada pelo modelo matemático avaliado, expressas como fração da irradiância $\left(\mathrm{I} / \mathrm{I}_{0}\right)$ disponível aos feijoeiros, podem ser visualizadas nas figuras 1 e 2 referentes à primeira e segunda épocas de semeadura respectivamente. 
Esses valores são relativos àqueles do piranômetro, representativos da condição de irradiância do feijoeiro em monocultivo. As frações médias da radiação disponível ao feijoeiro foram variáveis na semeadura de outono de 0,$20 ; 0,29 ; 0,28$; 0,50; 0,67 e 0,86 para as distâncias das árvores de 3,2; 4,$5 ; 6,3 ; 9,9 ; 14,4$ e $18,9 \mathrm{~m}$ respectivamente. O pequeno decréscimo da fração da radiação disponível da posição 2 para a 3 deve-se muito provavelmente à irregularidade da cobertura vegetal e, portanto, da sombra proporcionada pelas seringueiras.

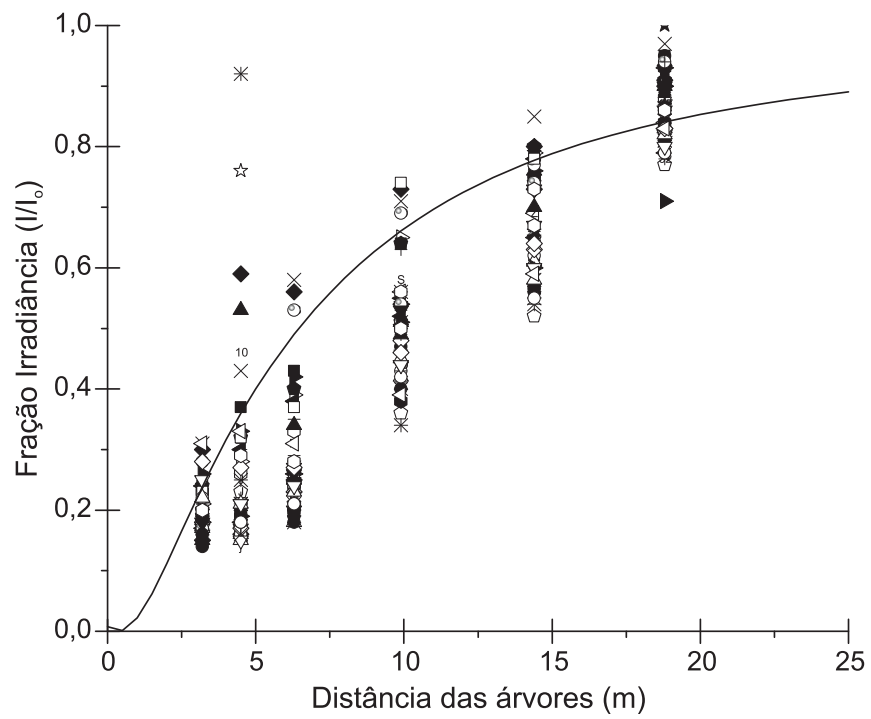

Figura 1. Disponibilidade de radiação mensurada (pontos) e simulada pelo modelo utilizado (-), em função da distância das árvores de seringueira, no outono. Piracicaba (SP), 1999.

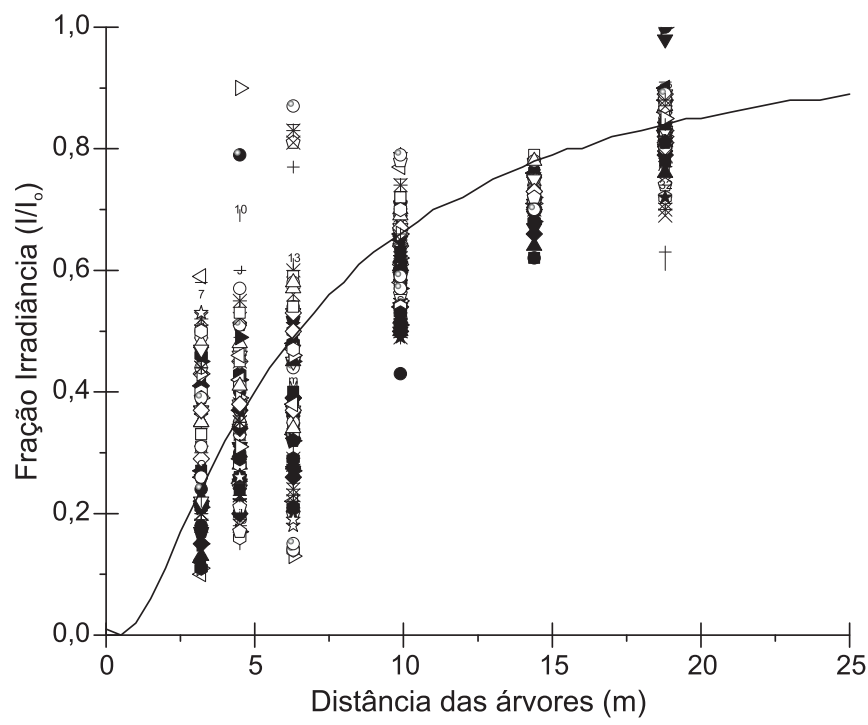

Figura 2. Disponibilidade de radiação mensurada (pontos) e simulada pelo modelo utilizado (-), em função da distância das árvores de seringueira, no inverno. Piracicaba (SP) 1999.
No cultivo de inverno essa variação foi de 0,$29 ; 0,35 ; 0,40 ; 0,61 ; 0,68$ e 0,83 para as mesmas distâncias das árvores. A variação da fração da irradiância disponível aos feijoeiros em uma mesma posição durante o período experimental deve-se às condições micrometeorológicas, tais como nebulosidade, irradiância, horas de insolação direta, etc. A fração da irradiância nas quatro primeiras distâncias foi, em média, 30\% maior no cultivo de inverno em relação ao de outono. Nesta interface pôde-se constatar a redução da irradiância disponível aos feijoeiros em ambas as épocas de cultivo, sendo mais acentuada durante a primeira época - estação de outono. De outro modo, durante o cultivo de inverno a radiação disponível aos feijoeiros nas linhas mais próximas das árvores foi maior até uma distância de 9,9 m das seringueiras. A partir da distância de 14,4 m das árvores, as frações de irradiância nas duas épocas foram similares. O aumento na fração da irradiância disponível aos feijoeiros durante o inverno foi decorrente da menor área foliar da seringueira, devido ao comportamento decíduo estacional desta espécie na região sudeste do país, padrão descrito por Righi et al. (2003) pela mensuração do seu IAF. Em ambas as épocas de cultivo, os valores estimados pelo modelo matemático utilizado foram bem aproximados aos medidos (Figuras 1 e 2), sendo adequadamente simulada a disponibilidade de radiação à cultura intercalar dada a presença das árvores em renque.

Na figura 3, vê-se a produtividade do feijoeiro, em $\mathrm{kg} \mathrm{ha}^{-1}$, obtida no cultivo de outono, em função da distância em metros das árvores. Pode-se verificar a maior produtividade do feijoeiro em monocultivo, sem interferência da seringueira, com produtividade média de $3.942 \mathrm{~kg} \mathrm{ha}^{-1}$. O menor valor foi $1.024 \mathrm{~kg}$ $\mathrm{ha}^{-1}$, obtido no tratamento mais próximo às árvores, na posição 1(3,2 m). Nas demais posições, os valores foram crescentes em direção ao monocultivo. Esses dados estão de acordo com VieIra (1967; 1985), que constatou um decréscimo na produtividade do feijoeiro em consórcio. Supõe-se que tal fato esteja relacionado direta e positivamente à disponibilidade de radiação à cultura do feijoeiro. Para STANTON (1971), as leguminosas, de modo geral, são responsivas à sombra com decréscimos de produção.

No cultivo de inverno, em geral, as produtividades dos feijoeiros, em termos absolutos, foram similares às do cultivo de outono, até $14,4 \mathrm{~m}$ de distância das árvores (Figura 4). Tal similaridade deve-se, provavelmente, a um aumento na fração da irradiância nas mesmas posições durante o cultivo de inverno. Nas seringueiras há acentuada cadufolia no inverno, na Região Sudeste do Brasil, obtendo-se 
valores mínimos de IAF no fim de julho/meado de agosto, como descrito por Righi et al. (2003). A influência das árvores no feijoeiro, na redução da irradiância disponível, nesta época do ano foi, portanto, menor do que durante o outono. No cultivo de inverno a redução na produtividade do feijoeiro, em função do sombreamento, foi menor e restrita à menor distância das árvores; esta interferência pôde ser observada até a distância de 9,9 m das árvores. Na primeira posição - 3,2 m de distância das árvores, a produtividade foi próxima à da mesma posição no cultivo de outono, com $907 \mathrm{~kg} \mathrm{ha}^{-1}$ (Figuras 3 e 4), sendo a posição com a menor produtividade obtida. A 9,9 m de distância das árvores, a produtividade de $2.228 \mathrm{~kg} \mathrm{ha}^{-1}$ foi igual à dos feijoeiros em monocultivo, já sendo superada na posição imediatamente seguinte - 14,4 m, com $2.435 \mathrm{~kg} \mathrm{ha}^{-1}$. Obteve-se o maior valor de produtividade a uma distância de $18,9 \mathrm{~m}$ das árvores, sendo de $2.620 \mathrm{~kg} \mathrm{ha}^{-1}$, enquanto no monocultivo, foram produzidos $2.176 \mathrm{~kg} \mathrm{ha}^{-1}$. Analisando-se a produtividade na última posição em relação às árvores - distância de $18,9 \mathrm{~m}$, e no monocultivo, verificou-se não haver diferença significativa pelo teste $\mathrm{F}$; neste caso, a probabilidade do valor de $\mathrm{F}$ foi 0,58 . Não foi observado, portanto, efeito positivo do sombreamento na produtividade dos feijoeiros. Nas demais posições, as produtividades foram $1.507 \mathrm{~kg} \mathrm{ha}^{-1} \mathrm{e} 1.589 \mathrm{~kg} \mathrm{ha}^{-1}$, respectivamente, para as distâncias de 4,5 e 6,3 m das árvores.

É interessante notar que, apesar do acúmulo de fitomassa superior nos feijoeiros do cultivo de

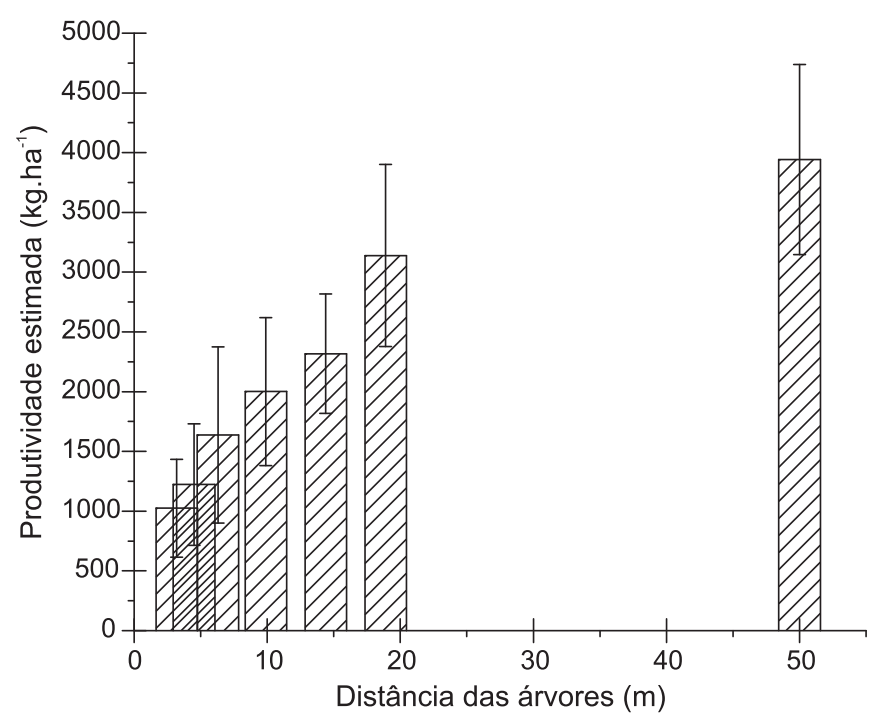

Figura 3. Produtividade do feijoeiro, cultivar Pérola, em kg $\mathrm{ha}^{-1}$, em função da distância em metros das árvores de seringueira no cultivo de outono. Piracicaba (SP), 1999.

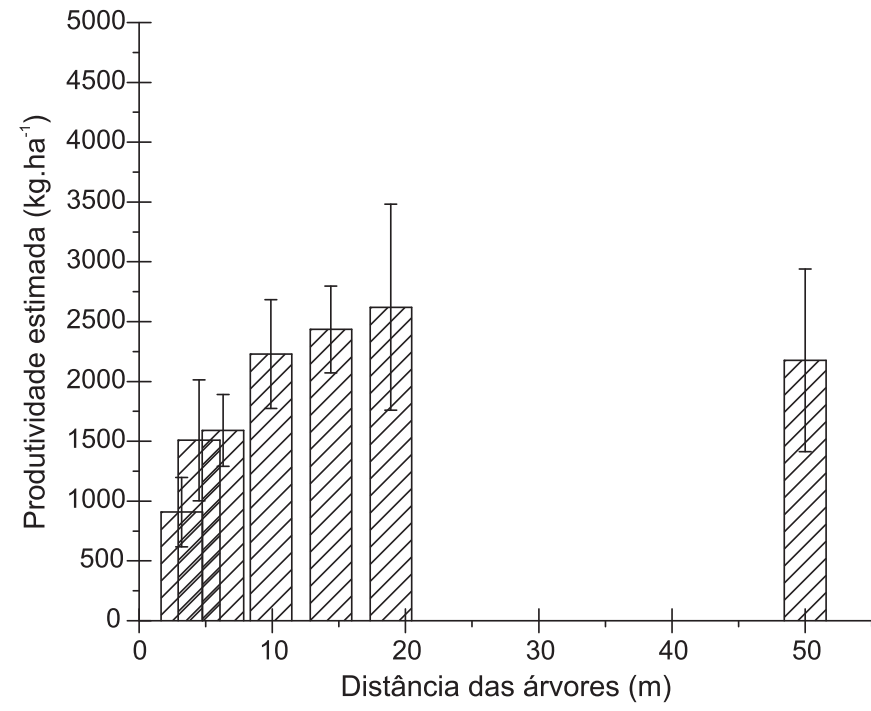

Figura 4. Produtividade do feijoeiro, cultivar Pérola, em kg ha $^{-1}$, em função da distância em metros das árvores de seringueira no cultivo de inverno. Piracicaba (SP), 1999.

inverno em relação aos do cultivo de outono, em quase todas as posições avaliadas, tal fato não resultou em maior produtividade. $\mathrm{O}$ acúmulo de fitomassa nos feijoeiros na primeira época de cultivo foi de 1.851; $2.359 ; 2.897 ; 3.692 ; 4.753 ; 5.658$ e $6.986 \mathrm{~kg} \mathrm{ha}^{-1}$ e de $2.626 ; 3.970 ; 4.175 ; 5.607 ; 6.201 ; 6.285$ e $5.627 \mathrm{~kg} \mathrm{ha}^{-1}$ no cultivo de inverno, respectivamente, para as distâncias das árvores de 3,2; 4,5; 6,3; 9,9; 14,4; 18,9 $\mathrm{m}$ e monocultivo do feijoeiro. Uma discussão mais detalhada a respeito do acúmulo de fitomassa nos feijoeiros pode ser consultada em Righi (2000). Em cada época de cultivo e, nos tratamentos com diferentes níveis de irradiância, o índice de colheita não foi negativamente afetado, sendo similar entre as diversas posições de avaliação; entretanto, foi superior no outono, com média de 0,54 , contra 0,38 do inverno. Apesar de na segunda época de semeadura, estabelecida no inverno, haver maior disponibilidade porcentual de irradiância, esta, em valores absolutos, não foi suficiente para maior indução do florescimento, sendo constatado somente, maior crescimento vegetativo. Contrariamente, BRENNER (1996) havia estabelecido que, com o sombreamento, poderia ser afetada a partição dos fotoassimilados, bem como o índice de colheita, em algumas culturas. Porém, PINTO et al. (2005) não obtiveram modificações deste índice em cana-de-açúcar submetida ao sombreamento ou ao pleno sol, como também ora relatado. É preciso levar em consideração que, em cana-de-açúcar, a parte colhida é constituída de órgãos vegetativos, ao contrário do feijoeiro.

A plotagem da fração de fitomassa produzida nos tratamentos, em relação à testemunha, versus a 
respectiva fração de irradiância disponível, é muito analisada por diversos autores para exame da matéria seca (Pinto et al., 2005; Righi, 2000; BLACK e ONG, 2000; LoOMIs e CONNOR, 1992); porém, pouco ou nada é comentado em relação à produção. Nas figuras 5 e 6 , verifica-se que a fração de produção do feijoeiro calculada pela relação entre a massa de grãos nos tratamentos e aquela no monocultivo - apresenta relação estreita e positiva com a fração de irradiância $\left(\mathrm{I} / \mathrm{I}_{0}\right)$ no topo das copas dos feijoeiros. Em ambas as épocas de cultivo, os coeficientes de correlação $\left(\mathrm{r}^{2}\right)$ das regressões lineares foram elevados e similares - 0,94 e 0,93 , respectivamente, no outono e inverno, indicativo de uma estreita dependência da produtividade para a irradiância.

$\mathrm{Na}$ produtividade do cultivo de outono verificou-se uma tendência mais próxima da relação 1:1. Assim pode-se constatar que, nesta época (Figura

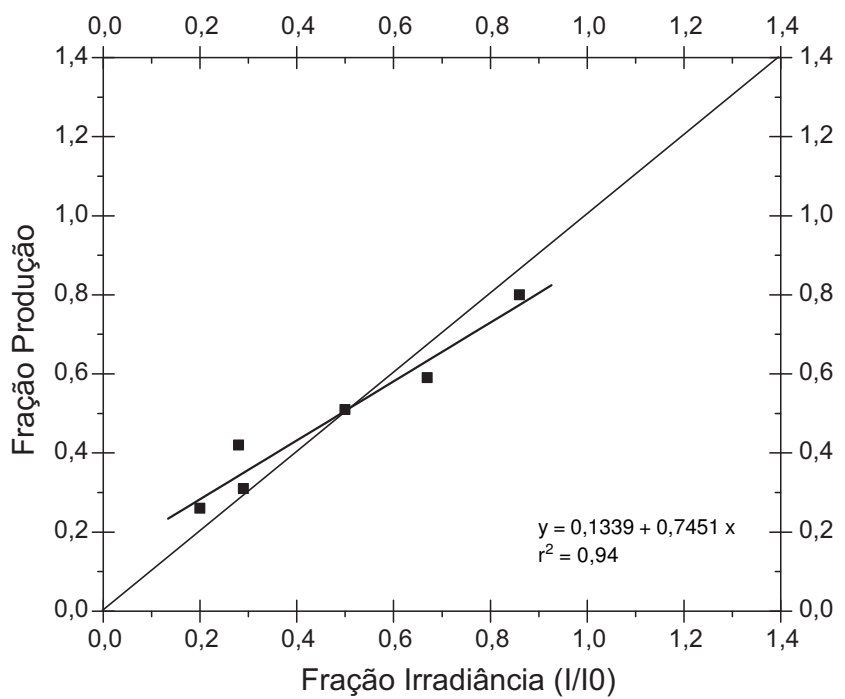

Figura 5. Correlação linear entre a massa relativa de grãos da cultura do feijoeiro, cultivar Pérola, e a fração da radiação disponível a estas em cultivo de outono. Piracicaba (SP), 1999.

5), o decréscimo na disponibilidade de radiação foi o principal fator para a redução na produção dos feijoeiros mais próximos das árvores, fato já relatado por Righi e BERnARDes (1999). Tem-se cruzamento da linha representativa dos dados de produção de grãos com a linha 1:1 na posição a 9,9 m de distância das árvores onde, com $50 \%$ da irradiância, obteve-se $50 \%$ da produtividade máxima alcançada. Nota-se que, para valores de radiação menores que este porcentual, a fração da produção obtida é relativamente cada vez maior. Isso faz com que o coeficiente angular da equação representativa dos pontos no cultivo de outono seja menor do que 1 , demonstrando aumento da eficiência no uso da radiação com a redução da fração de irradiância. Tais resultados também podem ser adicionalmente atribuídos ao aumento na área foliar específica nas posições com menor fração de irradiância, como observado por RigHI (2000).

Já no cultivo de inverno, a produção de grãos foi superior à proporção direta da radiação em todas as posições avaliadas (Figura 6). Tal fato poderia ser explicado pela maior eficiência no uso da radiação dos feijoeiros nessa época do ano. De qualquer forma, o coeficiente angular da equação representativa dos pontos no cultivo de inverno é maior do que 1 , o que demonstra o aumento da eficiência no uso da radiação com o aumento da fração de irradiância, em efeito contrário àquele observado no cultivo de outono. Tal fato sugere que as condições de radiação natural nesta época são subótimas para a produtividade do feijoeiro. Outra hipótese poderia ser a reduzida produtividade dos feijoeiros em monocultivo nessa época, expostos às grandes oscilações térmicas, fazendo com que, nas demais posições, fossem obtidas maiores frações de produtividade, ou ainda por um efeito protetor das árvores, efetivo nessa época do ano. Tal situação não foi constatada no monocultivo de outono quando as condições meteorológicas são consideradas boas ao desenvolvimento do feijoeiro.

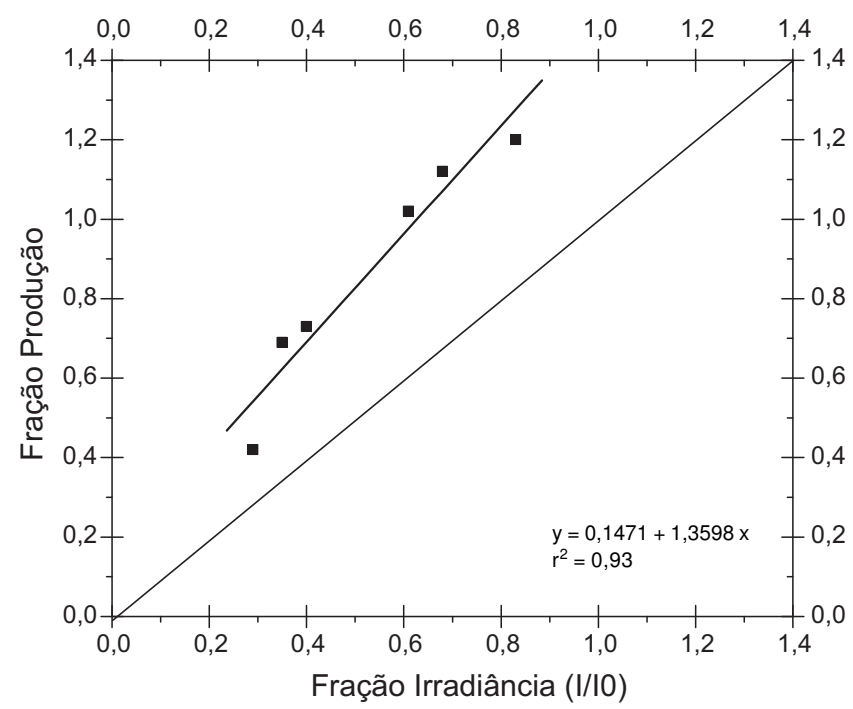

Figura 6. Correlação linear entre a massa relativa de grãos da cultura do feijoeiro, cultivar Pérola, e a fração da radiação disponível a estas em cultivo de inverno. Piracicaba (SP), 1999. 


\section{CONCLUSÕES}

1. A produção do feijoeiro está direta e positivamente relacionada com a disponibilidade de irradiância, podendo sua mensuração ou estimativa ser utilizada na predição de seu desempenho em SAF.

2. A irradiância disponível à cultura do feijoeiro, intercalar à seringueira, pode ser estimada por modelo matemático.

3. O sistema agroflorestal de seringueira e feijoeiro no outono e inverno é viável na região de Piracicaba (SP).

4. O índice de colheita do feijoeiro é diferente em cada época de semeadura, não sendo modificado em razão do sombreamento.

\section{AGRADECIMENTOS}

Os autores expressam seus agradecimentos à Fundação de Amparo à Pesquisa do Estado de São Paulo - FAPESP, pelo apoio financeiro para a execução desta pesquisa. Também agradecem ao Dr. Leonardo Médici, por sua ajuda na análise estatística e interpretação.

\section{REFERÊNCIAS}

BERNARDES, M.S. Simulation of agroforestry systems: the case of rubber tree associated with other crops. Wageningen, 1993. 63f. Programa (Doutorado) - Wageningen Agricultural University, Wageningen, Holanda.

BERNARDES, M.S.; GOUDRIAAN, J.; DOURADO NETO, D.; CÂMARA, G.M. de S. Tree-crop interactions in agroforestry system of rubber with soybean and maize. In: CONGRESS OF EUROPEAN SOCIETY FOR AGRONOMY, 5., 1998, República Eslovaca. Short Communications... República Eslovaca, 1998. vol. II, p. 125-126.

BLACK, C.; ONG, C.K. Utilization of light and water in tropical agriculture. Agricultural and Forest Meteorology, Amsterdã, v. 104, n. 1, p. 25-47, 2000.

BRENNER A.J. Microclimatic modifications in agroforestry. In: ONG C. K.; HUXLEY P. (Ed.). Tree-crop interactions: a physiological approach. Wallingford - Inglaterra: CAB International, 1996. cap. 5, p.158-187.

BURGA, C.A. Canopy architecture, light distribution, and photosynthesis of different dry bean (Phaseolus vulgaris L.) plant types. East Lansing, EUA, 1978. 1v. Tese (Ph.D.) - Michigan State University.

FANCELLI, A.L. A seringueira consorciada a culturas anuais e perenes. In: SIMPÓSIO DA CULTURA DA SERINGUEIRA, 2., Piracicaba, 1987. Anais... Piracicaba: ESALQ, 1990. p.205-22.
FANCELLI, A.L. Cultura do Feijão. Piracicaba: FEALQ/ ESALQ/USP, 1987.138p.

GARDINER, T.R.; VIETOR, D.M.; CRAKER, L.E. Growth habit and row width effects on leaf area development and light interception of field beans. Canadian Journal of Plant Science, Quebec, v.59, p.191-199, 1979.

GEPTS, P.; FERNÁNDEZ, F. Etapas de desarrollo de la planta de frijol comum (Phaseolus vulgaris L.). Cali, Colômbia: CIAT, $1982.10 \mathrm{p}$.

GOUDRIAAN, J. Crop micrometeorology: a simulation study. Wageningen: PUDOC, 1977. 249p. (Simulation Monographs)

LOOMIS, R.S.; CONNOR, D.J. Crop ecology: productivity and management in agricultural systems. Cambridge, Inglaterra: Cambridge University Press, 1992. 538 p.

NAIR, P.K.R. Soil productivity aspects of agroforestry. Nairobi: International Centre for Research in Agroforestry. 1984. 85p. (Science and Practice of Agroforestry, 1)

ONG C.K., CORLETT J. E., MARSHALL F.M., BLACK, C.R. Principles of resource capture and utilization of light and water. In: ONG C.K.; HUXLEY P. (Ed.). Tree-crop interactions: a physiological approach. Wallingford, Inglaterra: $C A B$ International, 1996. cap. 4, p. 73-158.

PEIXOTO, A. Feijão. Rio de Janeiro: Ministério da Agricultura - Serviço de Informação agrícola. 1958. 72 p. (Série Produtos rurais $n^{\circ} 8$ )

PINTO, L.F.G.; BERNARDES, M.S.; STAPE, J.L.; PEREIRA, A.R. Growth, yield and system performance simulation of a sugarcane-eucalyptus interface in a sub-tropical region of Brazil. Agriculture, Ecosystems and Environment, Amsterdã, v. 105, n. 1, p. 77-86, 2005.

RIGHI, C.A. Interações ecofisiológicas acima e abaixo do solo em um sistema agroflorestal de seringueira (Hevea brasiliensis) e feijoeiro (Phaseolus vulgaris). Piracicaba, 2000. 130f. Dissertação (Mestrado em Agronomia) - Escola Superior de Agricultura "Luiz de Queiroz", Universidade de São Paulo.

RIGHI, C.A.; BERNARDES, M.S.; CASTRO, D.S.; ABBUD, D.M. Fenologia e variação temporal do índice de área foliar de três cultivares de seringueira (Hevea spp.). Agrotrópica. Ilhéus, v.13, n.3, p. 125-132, 2003.

RIGHI, C.A.; BERNARDES, M.S. Modelo de atenuação de radiação para sistema agroflorestal de seringueira (Hevea brasiliensis) e feijoeiro (Phaseolus vulgaris). In: CONGRESSO BRASILEIRO DE FISIOLOGIA VEGETAL, 7., 1999, Brasília. Resumos... Revista Brasileira de Fisiologia Vegetal, Brasília 1999. v.11, p. 56. (Suplemento)

STANTON, W.R. Leguminosas de grano africanas. Roma: FAO. 1971. $162 \mathrm{p}$.

VIEIRA, C. O feijoeiro comum: cultura, doenças e melhoramento. Viçosa: Universidade Federal de Viçosa - Imprensa Universitária, 1967. 220 p. 
VIEIRA, C. O feijão em cultivos consorciados. Viçosa: Universidade Federal Viçosa - Imprensa Universitária, 1985. $134 \mathrm{p}$.

VILLA NOVA, N.A.; SENTELHAS, P.C. . Evapotranspiração máxima do feijoeiro, c.v. Goiano precoce, em função do índice de área foliar e da evaporação do tanque classe A. In: CONGRESSO DE AGROMETEOROLOGIA, 11., e REUNIÃO LATINO AMERICANA DE AGROMETEOROLOGIA, 2., Florianópolis, SC, 1999. Anais... Florianópolis, SC: Sociedade Brasileira de Agrometeorologia, 1999. v. 1. p. 212-218.

WHITE, J.W.; IZQUIERDO, J. Fríjol: fisiología del potencial del rendimiento y la tolerancia al estrés. Santiago, Chile: Oficina Regional de la FAO para América Latina y el Caribe, 1989. $91 \mathrm{p}$.
WILLEY, R.W.; REDDY, M.S. A field technic for separating above-and bellow interactions in intercropping and experiment with pearl millet groundnut. Experimental Agriculture, Inglaterra, Cambridge, v.17, p. 257-264, 1981.

YOUNG, A. Agroforestry for soil conservation. Wallingford, Inglaterra: CAB International, 1989. 276p.

ZHU, Z.; CAI, M.; WANG, S.; JIANG, Y. Agroforestry systems in China. Canadá: International Development Centre - The Chinese Academy of Forestry, 1981. 216 p. 